\title{
OPTIMALISASI KEARIFAN LOKAL PADA PENGAJARAN INTEGRATED LANGUAGE SKILL MENGGUNAKAN METODE BLENDED LEARNING
}

\author{
Elysa Hartati \\ Universitas Mercu Buana Yogyakarta Jl. Wates Km 10 Sedayu, Yogyakarta \\ Email: elysa@mercubuana-yogya.ac.id
}

\begin{abstract}
Abstrak: Masuknya budaya asing yang masif diduga akan membawa penurunan pengakuan budaya lokal oleh generasi muda khususnya anak-anak sekolah. Padahal, budaya lokal tersebut tetap dapat diajarkan secara terpadu dengan menyisipkan kearifan lokal melalui teks yang digunakan sebagai bahan dan media belajar mengajar khususnya pada mata pelajaran bahasa. Artikel ini bertujuan untuk memaparkan bagaimana mengoptimalkan kearifan lokal dalam pengajaran keterampilan berbahasa terpadu melalui metode blended learning. Dengan memanfaatkan pendekatan POACE (Planning, Organizing, Actuating, Controlling, and Evaluating), program pengabdian masyarakat ini dilakukan melalui platform daring berupa workshop. Program ini mendapat respon positif dari 50 peserta guru dan calon guru bahasa yang bergabung. Mereka juga menyadari pentingnya masalah ini untuk mencegah punahnya budaya lokal Mengintegrasikannya dengan teknologi ke dalam pengajaran bahasa bisa menjadi alternatif yang bisa dilakukan. Para siswa juga dapat mengenali budaya lokal mereka sendiri dengan mendapatkan beberapa teks yang berisi warisan budaya sambil belajar bahasa. Sementara itu, guru juga dapat berperan sebagai promotor budaya melalui materi ajar yang dibawanya ke dalam kelas. Dengan demikian, konservasi budaya dapat dilakukan oleh kedua pihak, yaitu guru dan siswa sebagai generasi muda.
\end{abstract}

Kata kunci: Budaya, kearifan lokal, keterampilan berbahasa terpadu, blended learning

\begin{abstract}
The massive involvement of the foreign culture is assumed to decrease the recognition of the local culture by young generations particularly the school-age ones. In fact, it could be still taught in integrated way by inserting the local wisdom through the discourse used as the teaching and learning materials and media especially in language subjects. This article aimed to present how to optimize the local wisdom in teaching integrated language skills through blended learning method. By making use of POACE (Planning, Organizing, Actuating, Controlling, and Evaluating) approach, this community service program was conducted through online platform in a form of a workshop. This program brought positive responses from 50 participants of language teachers and teacher candidates joining. They also realized the importance of this issue to prevent the local culture extinction. By integrating it with technology into language teaching, it could be an alternative to do. The students also could recognize their own local culture by gaining some texts containing cultural heritages while learning a language. Meanwhile, the teachers also could have a role as cultural promoters through teaching materials they bring into the class. Thus, culture conservation could be done by both parties, the teachers and students as the young generations.
\end{abstract}

Keywords: Culture, local wisdom, integrated language skills, blended learning.

\section{PENDAHULUAN}

Indonesia sangat terkenal dengan warisan budayanya yang kaya yang berisi nilai-nilai luhur yang patut untuk dilestarikan dan dipelajari khususnya bagi generasi-generasi muda yang saat ini mulai menurun peminatannya untuk mempelajari budaya. Hal ini juga ditegaskan oleh Gemilang (2010) yang menyatakan bahwa eksistensi produk budaya khususnya pertunjukan wayang Orang saat ini perlahan tampak mulai ditinggalkan terutama oleh generasi muda terbukti dengan sepinya pengunjung di semua gedung pertunjukan. Ada banyak warisan budaya yang mengandung kearifan lokal di dalamnya yang bisa dimanfaatkan oleh pengajar dalam hal ini adalah guru di lingkungan sekolah formal dalam pengajaran bahasa. Kearifan lokal menurut Gobyah (2003) dalam Ernawi (2010) dimaknai sebagai suatu 
kebenaran yang telah mentradisi atau ajeg dalam suatu daerah. Oleh karena itu, seyogyanya nilai-nilai positif yang diyakini dan menjadi pedoman nilai kehidupan daerah setempat yang terkandung di dalamnya tetap dijaga dan diwariskan kepada generasi-generasi muda.

Guru-guru yang berada di wilayah Daerah Istimewa Yogyakarta dan Jawa, sebagai lokasi dan target pengabdian ini dilaksanakan, bisa menyelipkan nilai-nilai kearifan lokal pada warisan budaya seperti wayang orang, rumah adat, baju adat, upacara adat, dll sebagai bahan atau materi pembelajaran dalam bentuk teks yang bisa disesuaikan dengan standar kompetensi maupun kompetensi dasar yang ada. Hal ini juga tidak terlepas dari aturan Permendikbud RI No. 37 Tahun 2018 bahwa guru seyogyanya bisa menjadi agen promosi budaya untuk peserta didiknya agar mereka mencintai warisan budaya lokal dengan mengintegrasikan kearifan lokal yang terkadung di dalamnya dalam pembelajaran. Hal ini pun bisa diadaptasi oleh para guru yang tersebar di berbagai penjuru di Indonesia bahkan di luar negeri dengan ciri khas budaya masing-masing dalam pengajaran bahasa.

Cultural Language Learning Approach (CLLA) menjadi pendekatan yang sangat sesuai untuk pengajaran bahasa dengan pengintegrasian budaya. $C L L A$ merupakan suatu pendekatan pembelajaran bahasa yang berfokus pada pemanfaatan muatan wacana menyangkut berbagai jenis warisan seni budaya tradisional seperti keris, gamelan, berbagai jenis wayang, rumah tradisional misalnya rumah Joglo, pakaian adat daerah, dan berbagai jenis tarian sebagaimana disimpan di beberapa museum nasional seperti Museum Nasional Sonobudoyo (Setiadi, 2017).

Untuk menyeimbangkan kebutuhan generasi muda saat ini di tengah teknologi yang berkembang, CLLA bisa diterapkan melalui Blended Learning Method (BLM). BLM diartikan sebagai campuran antara pembelajaran online dan tatap muka, di kelas atau di luar kelas, bersama guru atau pun tanpa guru (Thompson, 2016). BLM diterapkan untuk mengakses berbagai informasi terkait warisan budaya dari berbagai website, youtube, podcast, dan sumber lainnya untuk dipelajari secara individu maupun berkelompok dan selanjutnya dipresentasikan secara individu ataupun berkelompok melalui gawai yang peserta didik miliki.

Proses pembelajaran dilakukan dengan menggunakan materi warisan budaya yang salah satunya adalah rumah adat Jawa seperti Joglo, Panggang Pe, Limasan, Kampung, Tajug yang dipilih dari berbagai sumber website yang kemudian dideskripsikan sebagai salah satu contoh pengajaran teks deskriptif untuk pembelajaran reading-writing dalam peng- ajaran bahasa Inggris untuk kelas 7 Sekolah Menengah Pertama (SMP). Memadukan keterampilan bahasa (integrating language skills) juga menjadi salah satu fokus dalam pengabdian ini. Integrated Language Skills (ILS) adalah keterampilan berbahasa secara terpadu dan terintegrasi. Dalam memadukan keterampilan bahasa tersebut mengacu pada konsep receptive and productive skills. Menurut Brown (2007) receptive skill merupakan keterampilan menerima informasi dari sebuah teks sedangkan productive skill adalah keterampilan menghasilkan teks dari informasi yang diterima. Dalam kaitannya dengan konsep tersebut maka perpaduan keterampilan bahasa bisa disajikan dalam bentuk ListeningSpeaking, Reading-Writing, Listening-Writing, atau Reading-Speaking yang bisa disesuaikan dengan tujuan pembelajaran saat itu sesuai standar kompetensi dan kompetensi dasar yang tertuang dalam kurikulum yang berlaku. Di satu sisi, ILS ini sangat membantu di tengah keterbatasan jam pelajaran yang ada di sekolah. Guru bisa memadukan dua keterampilan sekaligus dalam satu jam pelajaran atau satu pertemuan.

Selain itu, dengan menyajikan wacana dalam bentuk teks, guru bisa mengeksplorasi keterampilan bahasa (language skills) seperti listening, speaking, reading, writing serta komponen bahasa (language components) seperti vocabularies, pronunciation, grammar, language expression, fluency, dll. Sistem pengajaran berbasis top-down sangat cocok dalam pembelajaran ini dengan menyajikan wacana secara terpadu. Teks bisa digunakan sebagai input sebagai prior knowledge bagi peserta didik, sedangkan guru bisa menjadi fasilitator dalam mengeksplorasi teks tersebut.

\section{METODE PELAKSANAAN}

Awalnya kegiatan pengabdian ini akan diberikan dalam bentuk pelatihan secara langsung (tatap muka) kepada guru-guru bahasa tingkat SMP atapun SMA di wilayah D.I. Yogyakarta dan sekitarnya. Namun, karena pandemi yang terjadi saat ini, konsep pelatihan tatap muka akhirnya diganti dengan online workshop yang mengundang guru maupun calon guru bahasa di Indonesia. Ada 50 peserta yang tergabung dalam kegiatan ini, yang terdiri dari mahasiswa, guru, dosen, maupun tutor bahasa. Kegiatan pengabdian ini menggunakan rancangan POACE (Planning, Organizing, Actuating, Controlling and Evaluating) yang meliputi 5 tahapan kegiatan sebagai berikut: (1) materials planning; (2) learning organizing; (3) language practice actuating; (4) learning activities controlling; dan (5) evaluation on the learning activities in a whole (Hermayawati \& Hartati, 2019). 


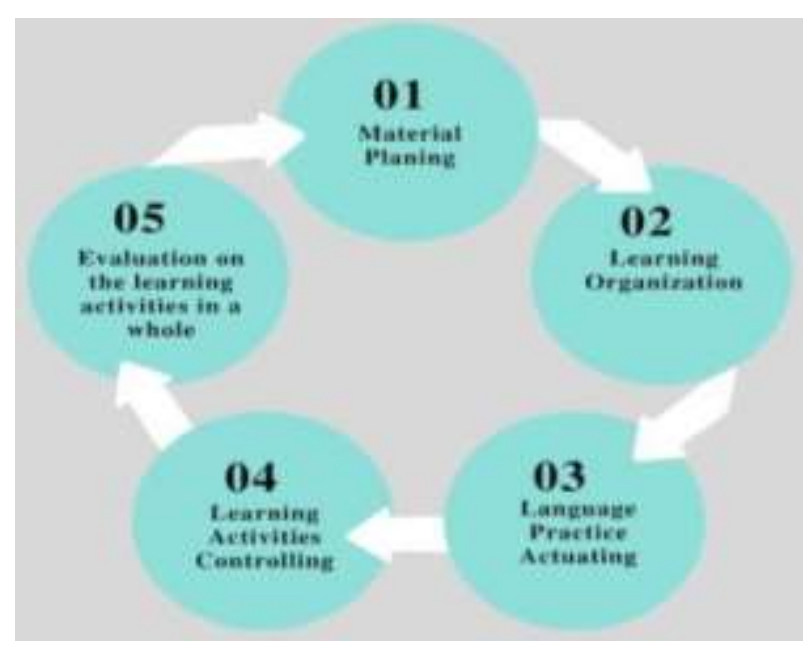

Gambar 1. Tahapan POACE

Prosedurnya meliputi perencanaan materi yang akan diberikan dengan melihat target peserta yang ada, penyusunan materi, penyampaian materi melalui workshop, pengontrolan kegiatan dengan melakukan observasi saat kegiatan berlangsung, serta pengevaluasian di akhir kegiatan.

Workshop ini disampaikan secara praktis dengan memberikan teori (30\%) dan praktik (70\%) agar peserta memahai bagaimana pengimplementasian nilai kearifan lokal yang terkandung dalam warisan budaya untuk pengajaran integrated language skills menggunakan metode blended learning. Workshop dilaksanakan selama kurang lebih tiga (3) jam dengan berbagai contoh pengaplikasian seperti wayang orang, rumah adat serta upacara adat Jawa dalam pengajaran bahasa.

\section{HASIL DAN PEMBAHASAN}

Hasil dari kegiatan pengabdian ini menunjukkan respon positif dari para peserta terkait pengintegrasian budaya dalam pembelajaran bahasa. Banyak dari peserta yang antusias mengajukan pertanyaan bagaimana pengimplementasian CLLA ini dalam pembelajaran bahasa. Banyak dari mereka yang ingin menerapkan konsep ini dalam pembelajaran bahasa sesuai konteks budaya masingmasing sehingga nilai kearifan lokal tetap terjaga. Beberapa peserta juga baru menyadari bahwa pembelajaran asing ternyata tidak selalu harus menggunakan produk budaya asing sebagai contoh teksnya. Bahkan produk budaya sendiri bisa digunakan sebagai contoh teks. Para guru dari pelatihan ini khususnya juga menyadari bahwa mereka adalah agen atau promotor budaya yang merupakan warisan leluhur sesuai amanat yang tertuang pada Permendikbud RI Th. 2018 yang seyogyanya disisipkan dalam pembelajaran bahasa.

Gambar 2, 3, dan 4 merupakan ilustrasi dari pelaksanaan pengabdian ini dengan menggunakan teks bermuatan budaya dan mengintegrasikan keterampilan bahasa di dalamnya dengan menggunakan Blended Learning Method.

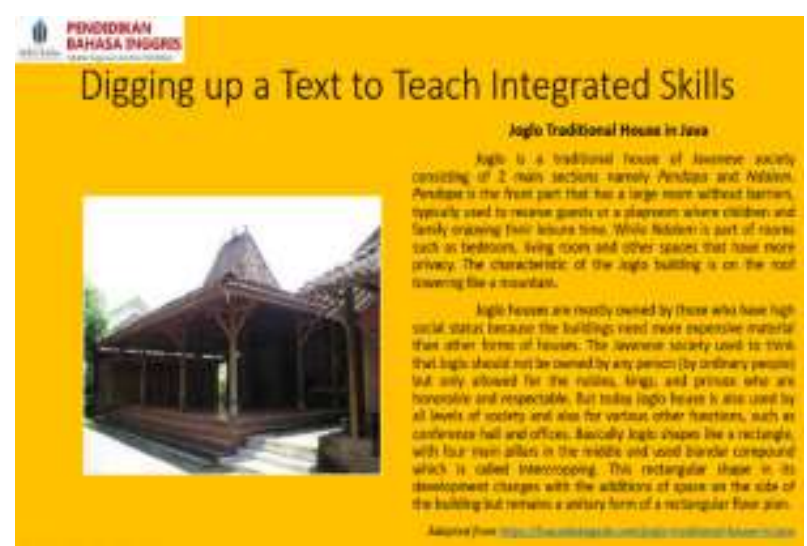

Gambar 2. Contoh Teks Deskriptif Bermuatan Kearifan Lokal

Sebelum workshop dimulai, peserta diajak untuk melakukan brainstorming terkait warisan budaya apa yang dimiliki di daerah masing-masing melalui aplikasi online yaitu menti.com. Dari sini, peserta mulai mengidentifikasi warisan budaya apa yang dimiliki di daerahnya serta mereka juga diajak untuk mengenali berbagai ragam rumah adat khususnya masyarakat suku Jawa seperti Joglo, Limasan, Panggang Pe, Kampung, dan Tajug. Hal ini dilakukan untuk membuka wawasan para peserta terkait materi yang akan dibahas supaya mendapatkan pemahaman yang sama sebelum masuk ke inti materi sebagai warming-up activity.

Pada gambar 2, ditunjukkan sebuah rumah Joglo, yang merupakan salah satu warisan leluhur berupa rumah adat di Daerah Istimewa Yogyakarta serta Jawa Tengah dan Jawa Timur. Disini dijelaskan makna filosofis dari bangunan rumah tersebut seperti bentuk arsitekturnya yang disusun sedemikian rupa. Deskripsi tentang rumah Joglo tersebut beserta nilai kearifan lokalnya dituangkan dalam sebuah teks berbahasa Inggris. Teks ini bisa digunakan untuk mengajar materi teks deskriptif dalam bahasa apapun. Siswa bisa memperoleh input atau informasi dari teks yang mereka baca. Tidak hanya pengayaan kosakata tetapi komponen bahasa yang lain seperti struktur bahasa juga bisa dipelajari dengan memadukan keterampilan bahasa yang lain seperti menyimak, berbicara, membaca dan menulis.

Gambar 3 menunjukkan contoh memadukan keterampilan bahasa. Secara praktis, hal ini bisa membantu guru membuat pembelajaran lebih efektif di tengah keterbatasan waktu yang diberikan. Dalam gambar 3, diberikan contoh bagaimana memadukan keterampilan bahasa dengan mengidentifikasi kata kunci "menangkap makna" dan "menyusun" teks ... dari kurikulum 2013 mata pelajaran bahasa Inggris kelas 7 Sekolah Menengah Pertama (SMP) yang saat ini digunakan di Indonesia. Dari kompetensi dasar yang sudah diidentifikasi, maka guru dapat menyusun tujuan pembelajaran yang mahasiswa harus capai di akhir pembelajaran. 


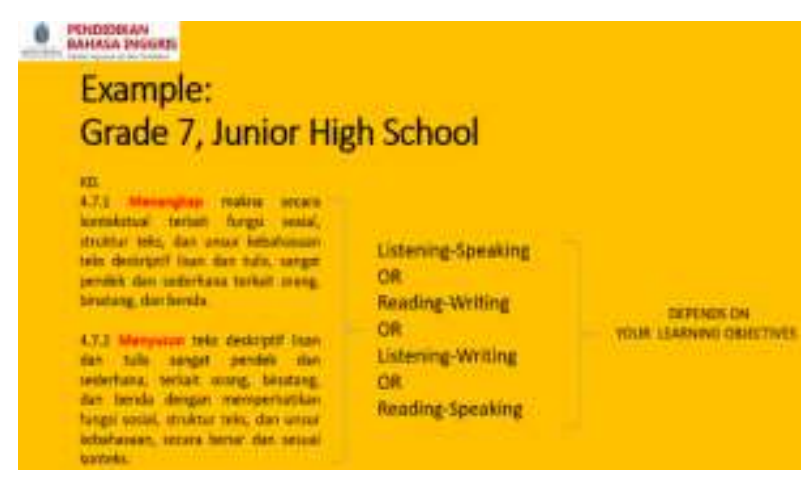

Gambar 3. Contoh Perpaduan Keterampilan Bahasa

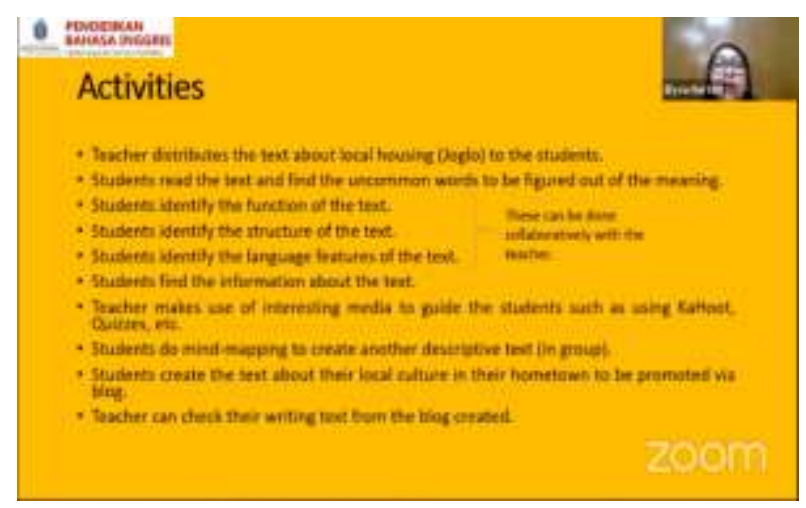

Gambar 4. Contoh Pengimplementasian Blended Learning Method

Gambar 4 memberikan simulasi bagaimana mengelola pembelajaran dengan mengintegrasikan kearifan lokal yang disajikan dalam sebuah teks. Topik yang digunakan adalah rumah adat Joglo yang dikemas menjadi sebuah teks deskriptif tertulis dengan fokus pembelajaran pada keterampilan membaca (receptive) dan menulis (productive). Aktivitas pembelajaran diarahkan terpusat pada siswa dengan pendekatan student-centered learning (SCL) yang mana dalam metode ini siswa dapat memperoleh kesempatan dan fasilltas untuk membangun sendiri pengetahuannya sehingga mereka akan memperoleh pemahaman yang mendalam dan pada akhimya dapat meningkatkan mutu kualitas dirinya (Haryono, 2017).

Siswa selanjutnya membaca dan menemukan kata-kata asing yang sekiranya menjadi fokus untuk dipelajari dan didiskusikan bersama. Mereka juga bisa mengidentifikasi fungsi, struktur, karakteristik bahasa yang digunakan serta informasi dari teks tersebut bersama-sama melalui online platform yang bisa digunakan seperti, KaHoot, Quizzes, Padlet, dan lain sebagainya. Setelah itu, siswa bisa mulai menulis teks deskripsi secara mandiri dengan memperhatikan karakteristik teks tersebut melalui blog dimana guru bisa memeriksa dan memberikan komentar sewaktu-waktu atau dibahas bersamasama di pertemuan selanjutnya. Fungsi dari penulisan blog ini adalah selain menjadikan siswa lebih melek dalam teknologi, juga tulisan tersebut bisa dibaca oleh umum yang mana hal ini juga selaras dengan misi dari pemerintah yaitu melestarikan budaya serta mempromosikan budaya lokal kepada khalayak ramai melalui pengajaran dan pembelajaran.

Hal ini merupakan perpaduan antara budaya yang mengandung banyak nilai kearifan lokal dengan teknologi melalui metode blended learning yang bisa saling terpadu untuk pengajaran dan pembelajaran bahasa.

Para peserta merasa sangat terbantu dari workshop ini, dan tergugah untuk melestarikan nilai-nilai kearifan lokal pada pembelajaran bahasa, khususnya bahasa asing. Hal ini ditunjukkan melalui sikap positif mereka saat sesi evaluasi. Mereka juga berharap ada workshop lebih lanjut untuk menggali lebih dalam praktik dari pengajaran berbasis CLLA.

\section{SIMPULAN}

Kegiatan pengabdian ini mampu menunjukkan bahwa dengan pengintegrasian budaya lokal dalam pembelajaran bahasa bisa membantu peserta didik untuk lebih sadar dan mengapresiasi budaya lokal mereka sendiri. Di sisi lain, guru bisa menjadi promotor budaya untuk generasi muda melalui materi atau teks dengan konten budaya yang mereka suguhkan dengan memadukan keterampilan bahasa (integrated language skills) kepada peserta didik.

Dengan demikian, budaya Indonesia yang sangat beragam dan kaya akan nilai kearifan lokal selalu bisa dipromosikan melalui generasi-generasi muda (peserta didik) dengan bantuan teknologi canggih yang sedang berkembang saat ini. Program pengabdian ini bisa menjadi alternatif bagi guru untuk mengasah kreativitas dalam pengajarannya sebagai agen perubahan untuk preservasi budaya yang kaya dengan nilai kearifan lokal di dalamnya.

\section{UCAPAN TERIMAKASIH}

Ucapan terima kasih saya haturkan kepada Universitas Mercu Buana Yogyakarta (UMBY) yang telah memberikan hibah pada pelaksanaan kegiatan pengabdian masyarakat ini. Juga terima kasih saya sampaikan kepada program studi Pendidikan Bahasa Inggris, Fakultas Keguruan dan Ilmu Pendidikan, UMBY yang telah membantu memfasilitasi keberlangsungan kegiatan.

\section{DAFTAR PUSTAKA}

Brown, H. D., 2007. Principles of Language Learning and Teaching. USA: Longman.

Ernawi, S. M., 2010. Makalah pada Seminar Nasional 'Urban Culture, Urban Future, Harmonisasi Penataan Ruang dan Budaya untuk Mengoptimalkan Potensi Kota'. http://www. penataanruang.net. [Diakses 10 November 2020]. 
Gemilang, G., 2020. Sesaji 100 Tahun Wayang Orang Sriwedari. https://aengaeng.com/2010/07/sesaji100-tahun-wayang-orang-sriwedari/. [Diakses 2 Juni 2020].

Haryono, A., 2017. Metode Student Centered Learning (SCL) dalam Pembelajaran Bahasa Asing dengan Media Berbasis E-Learning: Upaya Meningkatkan Peran Aktif dan Kreativitas Mahasiswa. http://repository.unej.ac.id/handle/ 123456789/83757. [Diakses 25 Juni 2021].

Hermayawati \& Hartati, E., 2020. Analisis Hasil Aktivasi Keterampilan Berbahasa Inggris Komunitas Pedagang Pasar Beringharjo. KoPeN: Konferensi Pendidikan Nasional, 2(1).

Permendikbud, RI., 2018. Perubahan Atas Peraturan Menteri Pendidikan dan Kebudayaan Nomor 24 Tahun 2016 Tentang Kompetensi Inti dan
Kompetensi Dasar Pelajaran Kurikulum 2013 pada Pendidikan Dasar dan Pendidikan Menengah. Jakarta: Kemendikbud.

Rebecca, 2001. Integrated Skills in the EFL/ESL Classroom. ERIC Digest. Washington DC: Oxford.

Setiadi, H., 2017. Designing a Supplementary Reading Using Cultural Language Learning Approach (CLLA). International Journal for Innovation Education and Research, 5(8), pp. 111-128.

Thompson, J., 2016. 6 Blended Learning Models: When Blended Learning is What's Up for Successful Students. https://elearningindustry. com/6-blended-learning-models-blended-learning-successful-students. [Diakes 4 November 2020]. 